\title{
IDENTIFICATION OF COEXISTING INDIGO SPECIES IN AN ANCIENT GREEN THREAD USING DIRECT PLASMON-ENHANCED RAMAN SPECTROSCOPY
}

\author{
FREDDY CELIS ${ }^{a *}$, CRISTIAN TIRAPEGUI ${ }^{b}$, MACARENA GARCÍA $^{a}$, ANDRÉS ARACENA $^{c}$, \\ ÁLVARO. E. ALIAGA ${ }^{d}$ AND MARCELO CAMPOS-VALLETTE ${ }^{d}$

\begin{abstract}
${ }^{a}$ Laboratorio de Procesos Fotónicos y Electroquímicos, Facultad de Ciencias Naturales y Exactas, Universidad de Playa Ancha, Subida Leopoldo Carvallo 270, Valparaíso, Chile.

${ }^{b}$ Instituto de Ciencias Químicas Aplicadas, Facultad de Ingeniería, Universidad Autónoma de Chile, El Llano Subercaseaux 2801, San Miguel, Santiago, Chile. ${ }^{c}$ Universidad de las Américas, Instituto de Ciencias Naturales, Manuel Montt 948, Santiago, Chile.

${ }^{d}$ Departamento de Química, Facultad de Ciencias, Universidad de Chile, P.O. Box 653 Santiago, Chile.
\end{abstract}

\begin{abstract}
A green ancient thread sample from a Chilean mummy turban was analyzed by plasmon-enhanced Raman scattering spectroscopy using a direct drop-colloidal method. The enhanced-Raman signals in the sample are associated with biomolecules from the thread and two coexisting dyes, indigo and leuco-indigo. The presence of indigo (blue colour) was identified from its most characteristic vibrational bands. Leuco-indigo (yellow colour) was identified for the first time in an ancient textile; its SERS signals are coincident with the SERS bands of a synthesized leuco-indigo. The interconversion leuco-indigo to indigo was followed by UV-visible spectroscopy. Based on theoretical calculations it is proposed that the interconversion involves a $\pi$ electron delocalization mainly around the NC-CN bridge. The mixture of both dyes (indigo and leuco-indigo) is the responsible for the green colour observed.
\end{abstract}

Keywords: Ancient thread, Indigo, Leuco-Indigo, Raman, SERS.

\section{INTRODUCTION}

Indigo, $(E)$-[2,2'-biindolinylidene]-3,3'-dione, is an organic compound used as dye due to its characteristic blue colour. Historically, indigo has been extracted from plants (Indigofera, Strobilanthes, Isatis, and Polygonum) [1-3] by ancient cultures to use it in a variety of artefacts and tangible cultural heritage of the humanity. Related to this fact, it has been reported $[4,5]$ that pre-Columbian cultures used fermented bath as a recurrently methodology for dyeing with indigo, where Clostridium bacteria is associated and described as a biochemical mediator of this particular dyeing process $[4,6,7]$. The identification of indigo in many different matrices has been usually carried out by several chromatographic methods $[1,3,8,9]$ and by spectroscopic techniques such as Raman and surface-enhanced Raman spectroscopy (SERS) [10-14].

The use of natural extracts from plants in dyeing process also considers the presence of many others indigo-derivatives. Maugard et al [1] detected by chromatography different coloured molecules derived from indigo such as transindigo (indigotin, blue), trans-indirubin (isoindigotin, red), cis-indigo (blue), cisindirubin (isoindirubin, red), indigo brown (isoindigo), indigo gluten and indigo yellow [1]. In the case of indigo yellow, no information about its identification as stable compound has been published, possibly, since its stability is associated to a particular chemical environment in the dyeing process. In this sense, synthetic indigo yellow or leuco-indigo, a water soluble diketo form of indigo (reduced form), is chemically unstable and in presence of $\mathrm{O}_{2}$ rapidly returns to its oxidized form (indigo). Leuco-indigo can be prepared by three chemical ways: dithionite pathway in a basic and inert $\left(\mathrm{N}_{2}\right)$ aqueous environment [15], catalytic hydrogenation [16] or electrochemical reduction [17].

Platania et al [18] developed a micro-extraction methodology for indigo from an ancient textile with subsequent reduction. The methodology consists in the use of reduction agents, called as leuco-reagents (sodium hydroxide and dithionite) in an agar-gel structure. The use of this method allowed the extraction of indigo in the reduced form, leuco-indigo, and its later characterization by Raman and SERS [18].

The presence of the yellow indigo has been reported in plants $[1,10]$. However, the possible existence of indigo related compounds in ancient textiles was studied in a lesser extent. In some particular cases green colours observed in certain textiles have been likely associated to the presence of indigo relatives. For instance, Otłowska et al [19] identified natural dyes in a $16^{\text {th }}$ century carpet from the combined use of chromatography and spectroscopy tools; a particular green sample was studied and the authors concluded that the colour is associated to the presence of indigo. However, no additional explanation of the colour was provided [19] considering that indigo exhibits a characteristic blue colour.

*Corresponding author email: freddy.celis@upla.cl
To our knowledge, there are no previous studies regarding the presence of leuco-indigo dye in ancient textiles. In the present work, we demonstrate for the first time the identification of leuco-indigo as a stable chemical species in a green thread from a Chilean mummy turban. This evidence was done by using SERS and a novel colloidal drop methodology on the sample experimented here that implies a non-extractive method of dye from the textile fibre. The results obtained by this way show the identification of the coexistence of two dyes: indigo and leuco-indigo. To support the presence of the leuco form, leuco-indigo was prepared in this work by chemical reduction of indigo, using dithionite in a basic and inert environment and its SERS spectrum was compared to that of indigo and the leuco-indigo referred in the literature.

\section{EXPERIMENTAL}

\section{Chemical reagents}

All the chemical reagents were of analytical grade and used without any further purification. Indigo, silver nitrate, sodium dithionite, sodium hydroxide, hydroxylamine hydrochloride and solvents were purchased from Sigma-Aldrich. Ultrapure water type 1 from Simplicity ${ }^{\circledR}$ water purification system was employed in the preparation of the silver nanoparticles (AgNPs) and the stock solutions.

\section{Instruments}

The colour measurement of the thread sample was performed in a Konica Minolta's CR-10 tristimulus colorimeter. The UV-visible spectra of the surfaceplasmon of the AgNPs, supernatants of the thread sample, indigo and leucoindigo in solution were recorded in a Hewlett Packard 8453 (Palo Alto, CA, USA) UV-visible spectrophotometer. Scanning Electron Microscopy (SEM) of AgNPs were obtained in a Zeiss EVO MA10, Oberkochen-Germany.

Raman and SERS measurements were performed in two instruments: a Micro-Raman system (RM1000, Renishaw) equipped with a Leica microscope and an electrically cooled charge coupled device (CCD) detector to analyze the dried samples; while a Witec Raman spectrometer model Alpha300 RA equipped with electrically cooled EMCCD detector model DU970-FI Newton Series was used to register the spectra in solution. The $785 \mathrm{~nm}$ laser line was employed in all the experiments. Spectra were recorded in the $200-1800 \mathrm{~cm}^{-1}$ region and the scanning conditions were chosen to avoid sample degradation.

\section{Preparation of the thread sample}

A green thread sample from a mummy turban belonging to the San Miguel de Azapa Archaeological Museum of the Universidad de Tarapacá in Arica, Chile, 
was analyzed. The turban was found in the Playa Miller 7 cemetery at "El Laucho" beach (see Figure S1, Supplementary Material) from the incipient agriculture period (formative) [20,21]. The analyzed sample consisted of several threads of $5 \mathrm{~mm}$ length. Commercial white wool was employed to register its Raman and SERS spectra as a blank in order to be compared with the ancient sample.

\section{Sample colour measurement}

The colour measured from the sample with the colorimeter was expressed according to the Commission Internationale de l'Eclairage (CIE) $L * a * b *$ colour space values [22-24], where each colour in the CIE L*a*b* colour space has a unique location defined by its Cartesian coordinates respect to the axes $\mathrm{L}^{*}, \mathrm{a}^{*}$ and $\mathrm{b}^{*}$; this is a 3-dimensional rectangular colour space based on the OpponentColours theory. $\mathrm{L}^{*}$ axis (lightness axis) has the following values: 0 for black, 50 for middle grey and 100 for white. In the $a^{*}$ axis (red-green axis), the positive value represents the red, a negative value for green and 0 is neutral. In the $b^{*}$ axis (blue-yellow axis), the positive value represents the yellow, a negative value the blue and 0 is neutral. The colour parameters measured for the sample were $\mathrm{L}^{*}$ : $33.1 ; a^{*}: 0.8 ; b^{*}: 10.7$. Based on these data, the colour of the sample is green.

\section{UV-visible Absorption spectra of the coloured solution from the thread}

UV-visible absorption spectra were obtained by extraction of the colorants of the green threads. To do this, the threads were deposited inside a glass tube containing $300 \mu \mathrm{L}$ of ultra-pure methanol; solutions were stored for 3 days in the darkness. Then, the supernatant solution was diluted with $1.5 \mathrm{~mL}$ of ultra-pure methanol and the UV-visible spectrum of the resultant solution was registered between 200 and $800 \mathrm{~nm}$ by using a quartz cell with $1.0 \mathrm{~cm}$ of optical path and a spectral resolution of $2 \mathrm{~nm}$.

\section{Synthesis and characterization of AgNPs}

AgNPs used in the SERS experiments were synthesized following previously reported methods [25]. This colloid was prepared by adding $10 \mathrm{~mL}$ of silver nitrate $\left(10^{-2} \mathrm{M}\right)$ to $90 \mathrm{~mL}$ of a solution containing hydroxylamine hydrochloride $\left(10^{-3} \mathrm{M}\right)$ and sodium hydroxide $\left(10^{-3} \mathrm{M}\right)$. The AgNPs were obtained at room temperature under rapid stirring conditions rendering a grey-reddish suspension. Extinction spectra of the suspension were obtained by diluting $200 \mu \mathrm{L}$ of the suspension in $0.8 \mathrm{~mL}$ of ultrapure water. The UV-visible spectrum of the resultant solution was registered in the 200 and $800 \mathrm{~nm}$ region by using a quartz cell with $1.0 \mathrm{~cm}$ of optical path and the spectral resolution of $2 \mathrm{~nm}$.

\section{Sample preparation for SERS measurements of the thread}

SERS analysis was always performed in-situ in order to preserve the integrity of the existing colorants. Thus, no hydrolysis procedure of the dye/mordant molecular system was applied. The preparation of the sample was carried out as follow: the thread was placed onto a single concave microscope slide and $25 \mu \mathrm{L}$ of colloidal suspension were dropped to cover the thread. The solvent was evaporated at room temperature without sunlight exposure. After three hours, the spectra were registered on different sites of the sample.

\section{Preparation of leuco-indigo in solution}

$3,3 \mathrm{mg}$ of indigo were added to $25 \mathrm{~mL}$ of ultrapure water. The resulting suspension was sonicated for 30 minutes. $300 \mu \mathrm{L}$ of this solution were added to a cuvette containing $54 \mathrm{mg}$ of sodium dithionite dissolved in $3 \mathrm{~mL}$ of $\mathrm{NaOH}$ (2M) solution in order to induce the oxidation of indigo to leuco-indigo. The cuvette was then sealed, and nitrogen gas was bubbled for 4 hours to prevent the oxidation of leuco-indigo and kept in the darkness for 12 hours. The resulting yellow leuco-indigo solution was studied by UV-visible and SERS. Once it was identified, small amounts of air volumes were added to oxidize the leuco-indigo to the indigo form. During this process, UV-visible spectrum was recorded.

\section{Raman and SERS measurements of indigo and leuco-indigo}

Regular Raman spectrum of indigo was obtained in the solid, while the SERS spectrum was obtained from the solution prepared by dissolving indigo in acetone to a final concentration of $1,0 \mu \mathrm{M}$. Then, $10 \mu \mathrm{L}$ of this solution was added to $200 \mu \mathrm{L}$ of AgNPs. The Raman and SERS spectra of indigo and sample were registered with a micro-Raman system (RM1000, Renishaw). The laser power onto the Ag colloidal coated sample was less than $2 \mathrm{~mW}$. The instrument was calibrated using the $520 \mathrm{~cm}^{-1}$ band of a $\mathrm{Si}$ wafer and a $50 \times$ objective. Its resolution was set to $4 \mathrm{~cm}^{-1}$ and 1-4 scans of 10-20 s each were averaged. Spectra were recorded in the $1800-200 \mathrm{~cm}^{-1}$ region. Spectral recording conditions and the laser line used were specially selected in order to avoid sample degradation and fluorescence background; in this sense, the $785 \mathrm{~nm}$ line was used.

SERS spectrum of leuco-indigo in aqueous solution was recorded in a Witec Raman spectrometer model Alpha300 RA equipped with electrically cooled EMCCD detector model DU970-FI Newton Series. The $785 \mathrm{~nm}$ laser line was employed to irradiate the aqueous solution into a quartz cuvette accessory. The excitation wavelength was chosen to avoid the intrinsic fluorescence of leucoindigo in aqueous solution.

\section{Theoretical calculations}

The Gaussian 09 software was employed to optimize the geometry of indigo and leuco-indigo and to calculate their Raman spectra; calculations were carried out at the DFT level using the restricted B3LYP functional and 6-31G(d,p) basis set in gas phase. Non-negative frequencies were obtained.

Geometry optimizations, geometry single point, scans and Raman frequencies calculations for indigo and leuco-indigo molecules in the gas phase were performed with the Gaussian 09 software [26]. The same dihedral angles NC-CN in indigo and leuco-indigo species were rotated in 45 steps of 8 degrees. The total energies and Raman spectra of conformers were obtained using the density functional theory DFT with the hybrid functional B3LYP (Becke's three parameter hybrid functional combined with the Lee-Yang-Parr correlation functional) and adopting the 6-31G (d,p) basis set. We selected the most representative conformer for each species according to the experimental data match. No imaginary frequencies were observed in the calculations of the vibrational spectra, and no scale factor was used in all the calculated frequencies. Local nucleophilic Fukui functions of the two species were analyzed by the AOMIX software [27].

\section{RESULTS AND DISCUSSION}

\section{AgNPs characterization}

The extinction maximum of the fabricated AgNPs was observed at $405 \mathrm{~nm}$, that indeed corresponds to its localized surface plasmon resonance, Figure 1A The analysis of AgNPs with SEM shows spherical nanoparticles, see insert in Figure 1A.

No Raman signals were observed except for the $241 \mathrm{~cm}^{-1}$ band assigned to the $\mathrm{Ag}-\mathrm{Cl}$ stretching mode [28]. In particular, $\mathrm{Cl}^{-}$anion comes from the colloidal preparation due to the use of hydroxylamine hydrochloride as a reducing agent, Figure 1B

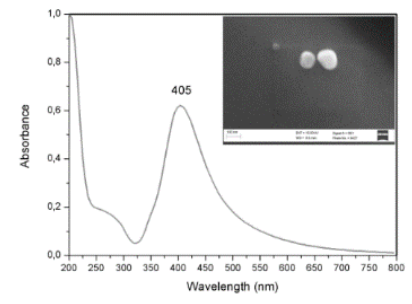

A)

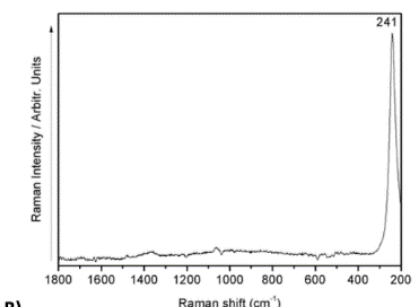

Figure 1. A) UV-visible spectrum and SEM image of spherical AgNPs. B) Raman spectrum of AgNPs.

\section{Raman and SERS analysis of the commercial white wool and thread sample}

Commercial white wool used as reference was analyzed by Raman and SERS (Figure 2). The Raman reference spectra of wool were compared to the corresponding SERS spectrum of the archaeological thread (Figure 2A). The SERS spectra on the thread was repeated in different points in order to check the effect of the laser radiation on the textile fiber (Figure S2). It is evidenced that no big variations were observed so it is ruled out any degradation during the experimental work 
The signals with significant relative intensities observed in the Raman spectrum of the white wool, were related to the presence of the amino acids of keratin. Tryptophan (W; $\left.1339 \mathrm{~cm}^{-1}\right)$, tyrosine $\left(\mathrm{Y} ; 1187\right.$ and $\left.836 \mathrm{~cm}^{-1}\right)$, cysteine (C; 652 and $522 \mathrm{~cm}^{-1}$ ) and phenylalanine $\left(\mathrm{F} ; 1630,1601,1004\right.$ and $962 \mathrm{~cm}^{-1}$ ) were the amino acids identified in the Raman profile, as it can be seen in Figure 2C. Additionally, bands due to $-\mathrm{CH}_{2}$ - deformations and amide III modes were also identified and assigned. The same signals of the latter amino acids were observed in the SERS spectrum of the blank (white wool), with different relative intensities and slight shifts according to the rigid structure of the keratin. A detailed assignment of these signals is listed in Table $\mathbf{1 .}$

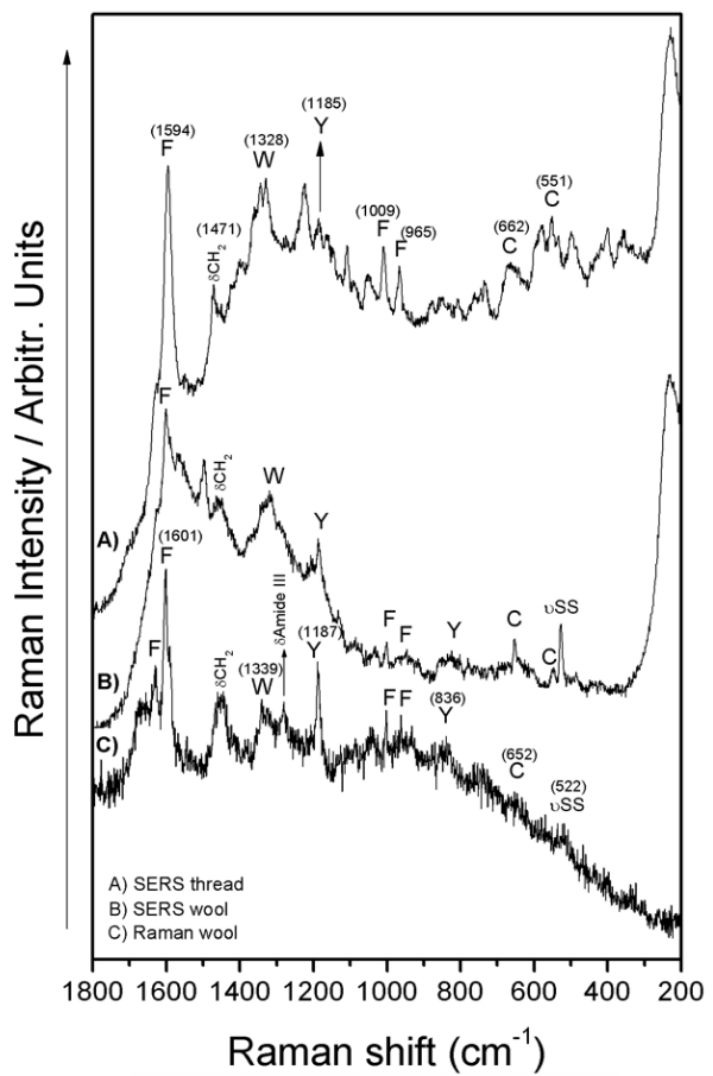

Figure 2. A) SERS spectrum of the thread sample, B) SERS spectrum of the white wool and $\mathbf{C}$ ) Raman spectrum of the white wool, including their bands assignment. ( $\delta$ : bending mode; $v$ : stretching mode).

Table 1: Comparison of some Raman and SERS bands $\left(\mathrm{cm}^{-1}\right)$ of the white wool with the SERS bands of the thread sample, along with the bands assignment.

\begin{tabular}{|c|c|c|c|}
\hline $\begin{array}{c}\text { Raman } \\
\text { white wool }\end{array}$ & $\begin{array}{c}\text { SERS } \\
\text { white wool }\end{array}$ & $\begin{array}{c}\text { SERS } \\
\text { thread Sample }\end{array}$ & Assignment \\
\hline $\mathbf{5 2 2}$ & 529 & - & $v$ S-S keratin \\
\hline- & 551 & 551 & C \\
\hline $\mathbf{6 5 2}$ & 650 & 662 & C \\
\hline $\mathbf{8 3 6}$ & 825 & - & F \\
\hline $\mathbf{9 6 2}$ & 950 & 965 & F \\
\hline $\mathbf{1 0 0 4}$ & 1004 & 1009 & Y \\
\hline $\mathbf{1 1 8 7}$ & 1184 & 1185 & W \\
\hline $\mathbf{1 2 8 1}$ & - & - & $\delta$ Amide III keratin \\
\hline $\mathbf{1 3 3 9}$ & 1316 & 1328 & F \\
\hline $\mathbf{1 4 5 5}$ & 1466 & 1471 & F \\
\hline $\mathbf{1 6 0 1}$ & 1601 & 1594 & - \\
\hline $\mathbf{1 6 3 0}$ & - & - & keratin \\
\hline
\end{tabular}

$\delta$ : in-plane deformation; $v$ : stretching; $C$ : cysteine; $Y$ : tyrosine; $F$ : phenylalanine; W: tryptophan.

\section{Analysis of the coloured sample}

In the SERS profile of the green sample it was possible to observe the same biochemical components of the keratin macrostructure [29, 30]. In particular, cysteine bands were observed at 551 and $662 \mathrm{~cm}^{-1}$. The first band is assigned to the stretching S-S mode of the gauche-gauche conformation which is supported by the appearance of the second band at $662 \mathrm{~cm}^{-1}$ assigned to the stretching C-S gauche $[31,32]$. Tyrosine is identified by the signal at $1185 \mathrm{~cm}^{-1}$ assigned to the out-of-plane deformation of the ring $(\mathrm{CCH})$. The strong signal at $1594 \mathrm{~cm}^{-1}$ was assigned to the ring stretching vibration of phenylalanine; this amino acid displays two other bands at 1009 and $965 \mathrm{~cm}^{-1}$. Finally, the signal at $1328 \mathrm{~cm}^{-1}$ is related to tryptophan benzene ring vibrations [33].

The green colour of the sample is rarely observed in ancient textiles. However, a recent study associates this colour with the presence of indigo derivates [19] without any other chemical structural specification.

The SERS spectrum of the green thread sample displays bands at 760, 879, 1047, 1230 and $1361 \mathrm{~cm}^{-1}$ which evidence the presence of indigo dye (Figure 3 Table 2). These bands can be assigned as follow [18, 34, 35]: the deformations of aromatic rings of six- and five-members are observed at 760 and $879 \mathrm{~cm}^{-1}$. The signal at $1047 \mathrm{~cm}^{-1}$ is assigned to the out-of-plane deformation of $\mathrm{CO}$ coupled to the stretching $\mathrm{CC}$ of aromatic rings, while the $\mathrm{CH}$ deformation is observed at $1230 \mathrm{~cm}^{-1}$. The band at $1361 \mathrm{~cm}^{-1}$ is attributed to a coupled vibration of the fragment composed by the $\mathrm{C}=\mathrm{C}, \mathrm{C}=\mathrm{O}$ and $\mathrm{N}-\mathrm{H}$ bonds.

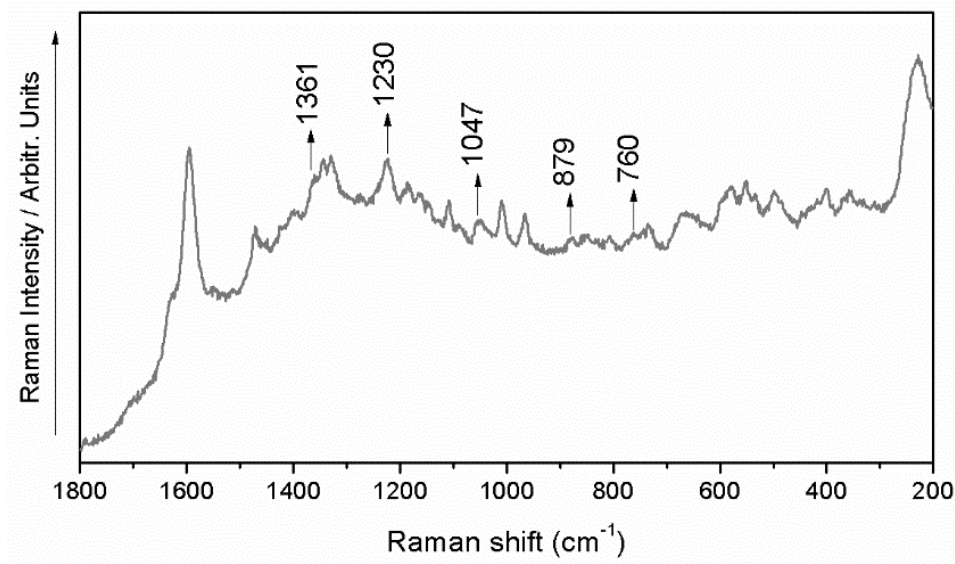

Figure 3. SERS spectrum of the green sample. Identified peaks are ascribed to indigo.

Table 2: Comparison of the most significant vibrational bands $\left(\mathrm{cm}^{-1}\right)$ in the SERS spectra of white wool, thread sample, leuco-indigo, indigo and their most probable bands assignment.

\begin{tabular}{|c|c|c|c|c|}
\hline $\begin{array}{c}\text { Raman } \\
\text { Indigo }\end{array}$ & $\begin{array}{c}\text { SERS } \\
\text { Indigo }\end{array}$ & $\begin{array}{c}\text { SERS } \\
\text { leuco-Indigo }\end{array}$ & $\begin{array}{c}\text { SERS } \\
\text { Sample }\end{array}$ & Assignment \\
\hline $\mathbf{5 4 5}$ & 544 & 549 & 551 & $\delta$ C=C-CO-C, $\delta$ C-N \\
\hline $\mathbf{7 5 8}$ & 759 & - & 760 & $\begin{array}{c}\text { Ring def. } \\
\text { and 5-member) }\end{array}$ \\
\hline- & - & 859 & 851 & $\delta$ Pyrrole \\
\hline $\mathbf{8 7 1}$ & 872 & - & 879 & Ring def. (6- and 5-member) \\
\hline & - & 1010 & 1010 & $\begin{array}{c}v \text { Ring-COH }+ \\
\text { Coupled to F breathing in the } \\
\text { sample }\end{array}$ \\
\hline- & 1058 & - & 1047 & Ring def. (5-member) and $\delta$ C=O \\
\hline- & 1110 & 1103 & 1107 & $\gamma$ C-H \\
\hline- & - & 1193 & 1185 & $\delta$ NC-CN bridge \\
\hline $\mathbf{1 2 3 1}$ & 1231 & 1243 & 1230 & $\gamma$ C-H $+\gamma$ N-H \\
\hline- & - & 1338 & 1345 & $\delta$ NC-CN bridge \\
\hline $\mathbf{1 3 7 4}$ & 1369 & 1368 & 1361 & $v$ C=C, $v$ C=O, $v$ N-H \\
\hline
\end{tabular}

Def. Deformation; $\delta$ : in-plane deformation; $\gamma$ : out-of-plane deformation; $v$ : stretching; $F$ : phenylalanine. 
The green colour observed in the threads is attributed to a combination of two coexisting species, the indigo blue colour and an indigo derivative contributing to the yellow coloration. The evident predominance of the indigo bands in the SERS spectrum is attributed to the stronger resonance effect of original blue indigo when exciting at $785 \mathrm{~nm}$. In order to corroborate the co-existence of these two indigoid forms, the synthesis of the yellow leuco-indigo was performed in order to be characterized by SERS.

Indigo displays a blue colour in aqueous solution and after the addition of dithionite the solution turns to yellow evidencing the formation of leuco-indigo (Figure 4A). The UV-visible spectrum of indigo (Figure 5A, dashed line), in a $60 / 40 \mathrm{v} / \mathrm{v}$ acetone-water solution, exhibits a single absorption maximum at 616 $\mathrm{nm}$ consistent with reported data [36,37]. Conversely, in aqueous solution after the addition of dithionite, this maximum disappears and it can be seen a new band at $410 \mathrm{~nm}$ (Figure 5A, solid line) associated to an absorption maximum of the synthesized leuco-indigo [36, 37]. The origin of the colour change from blue to yellow is explained by the UV-visible spectra differences [10]; the spectral modification is associated to a $\pi$ electrons delocalization around the pyrrole fragment and the $\mathrm{C}=\mathrm{C}$ bridge

As it can be seen in Figure 4B, the conversion of indigo to leuco-indigo involves the reduction of the indigo molecule with the subsequent loss of the $\mathrm{C}=\mathrm{C}$ double bond character on the bridge connecting the indole moieties.

A)
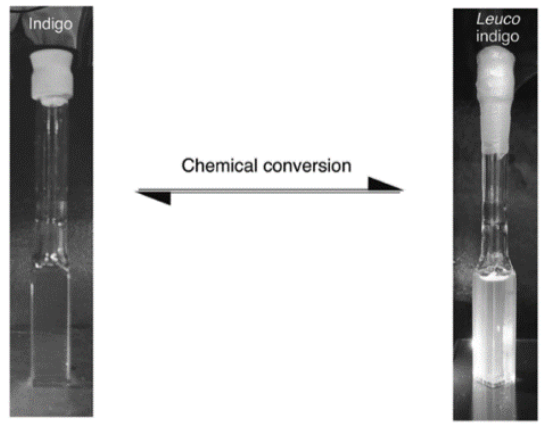

B)<smiles>O=C1NC2(CCCCC2)C2=C1C(=O)C(=C1NNc3ccccc31)N2</smiles>
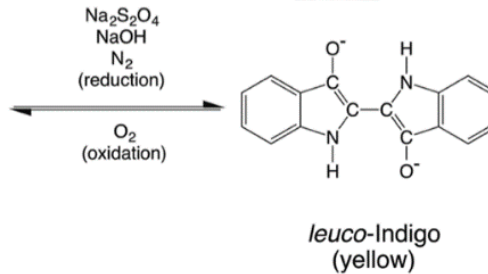

Figure 4. A) Picture of indigo and leuco-indigo aqueous solutions. B) Redox reaction of indigo to leuco-indigo.
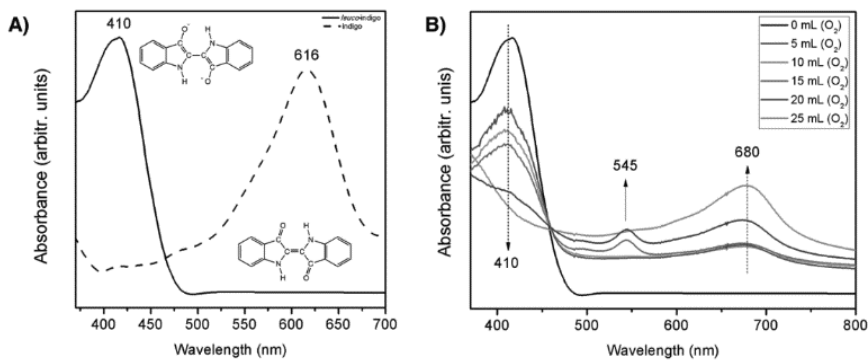

Figure 5. A) UV-visible spectra of indigo (dashed line) and leuco-indigo (solid line). B) UV-visible spectra of the leuco-indigo solution with 0, 5, 10, 15, 20 and $25 \mathrm{~mL}$ of oxygen adding.

This reduction can be reversed by the addition of oxygen to the leuco-indigo solution. To corroborate this fact, the conversion process of the synthesized leuco-indigo to indigo was performed by bubbling oxygen several times into the cuvette. UV-visible spectroscopy was used to monitor the conversion process. Figure 5B presents the UV-visible spectra of the leuco-indigo solution with 0,5, $10,15,20$ and $25 \mathrm{~mL}$ of oxygen. When oxygen is bubbled into the leuco-indigo solution, the band at $410 \mathrm{~nm}$ (leuco-indigo absorption maximum) starts to decrease its intensity (hypochromic effect). Simultaneously, a new band at 680 $\mathrm{nm}$ appears (indigo adsorption maximum) and increases its intensity (hyperchromic effect) with formation of an isosbestic point. After $25 \mathrm{~mL}$ of oxygen addition, there are no spectral signals of leuco-indigo; the UV-visible spectrum is dominated by the indigo signal. The stoichiometric addition of $\mathrm{O}_{2}$ into the cuvette revealed the formation of an intermediate of the reaction (Figure 5B), which is associated to the appearance of the band at $545 \mathrm{~nm}$ at the first addition of oxygen but quickly disappears. The low stability of this red coloured intermediate makes impossible to register its Raman or SERS spectra.

Related to the bathochromic shift of the absorption band observed in the UVvisible spectrum of the interconverted indigo from leuco-indigo (from 616 to 680 $\mathrm{nm}$, Figure 5A and $\mathbf{B}$ ), this could be related with the presence of the sodium cation (from sodium dithionite). To clarify this, TD-DFT calculations were performed (see supporting material). In particular, the UV-visible spectrum was simulated for indigo in presence and absence of two $\mathrm{Na}^{+}$cations. The obtained results exhibit a red shift of the absorption band when sodium cations were placed at $2.5 \AA$ of distance for each oxygen atom of indigo. The stabilization of the structure was achieved and a bathochromic shift from 535.88 to $632.44 \mathrm{~nm}$ $(+96.56 \mathrm{~nm})$ in the theoretical electronic UV-visible spectra in gas phase was observed (see Figure S3). On the other hand, a similar behavior was found by Liu et al [38], were the synthesis of indigo was achieved through the oxidation of indole by the use of $\mathrm{H}_{2} \mathrm{O}_{2}$ and a protein catalyst named as $\mathrm{F} 34 \mathrm{Y} \mathrm{Mb}$. In this case, the in-situ synthesis was followed by UV-visible spectroscopy, by considering the appearance of a band at $670 \mathrm{~nm}$ assigned to the formed indigo. When indigo is removed from the reaction aqueous solution and re-dissolved in DMF the absorption maximum exhibit a blue shift from 670 to $610 \mathrm{~nm}$. In this sense, it can be notice that the complexity of the reaction media can have an effect in the electronic behavior of the synthetized dye.

In order to demonstrate the presence of both leuco-indigo and indigo in the thread sample, an UV-visible spectrum was quickly obtained for the supernatant fraction of the solution of the thread in methanol. The absorption bands at 409 and $602 \mathrm{~nm}$ (Figure 6), are close with those observed in the UV-visible profile of indigo and the synthesized leuco-indigo displayed in Figure 5A.

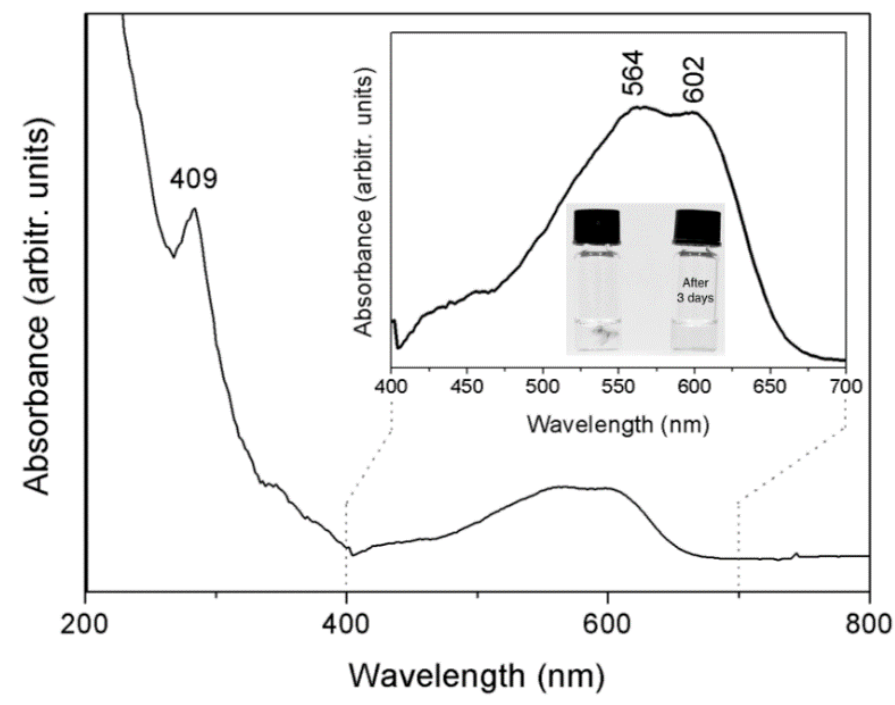

Figure 6. UV-visible spectrum of the supernatant solution.

SERS spectrum of the synthetized leuco-indigo is displayed in Figure 7C compared to those of indigo and the green thread. The most significant bands are listed in Table 2. No bands associated with anhydrous, hydrated or aqueous dithionite residues were observed in the SERS experiments of leuco-indigo $[38,39]$. In general, the SERS spectrum of leuco-indigo is dominated by bands of medium and strong relative intensity at 551, 859, 949, 1010, 1103, 1193, 1338, 1571 and $1612 \mathrm{~cm}^{-1}$ (Figure 7C). Most of these bands have been also observed and discussed by Platania et al [18]. However, they did not make any assignment for the 1193 and $1338 \mathrm{~cm}^{-1}$ signals, which are associated with the pyrrole ring fragment and the conjugated NC-CN bridge. These two bands are of great importance because they are directly related to the moiety of the chemical structure that differentiates leuco-indigo from indigo. 


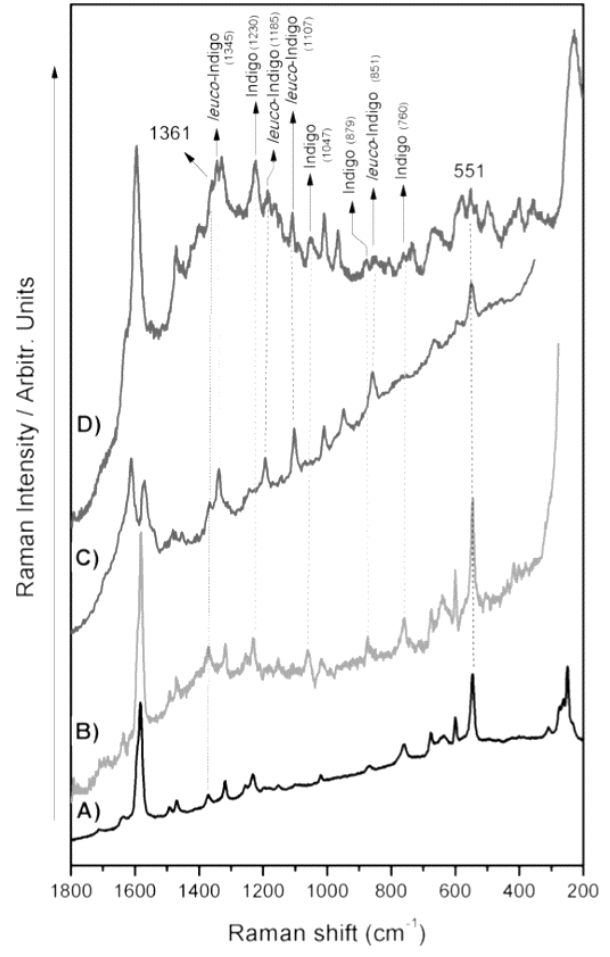

Figure 7. A) Raman and B) SERS spectra of indigo. C) SERS spectrum of leuco-indigo and D) SERS spectrum of the green dyed thread sample.

In order to find an appropriate assignment of the bands 1193 and $1338 \mathrm{~cm}^{-1}$, a theoretical study was performed for two selected conformers displaying differences mainly in their dihedral angle associated to the NC-CN bridge. The proposed theoretical bands assignment suggests coupled vibrational modes with an important contribution of a stretching vibration of a rather single C-C bond and vibrations of the 6- and 5-member ring for both bands (Table 3). This is consistent with the possibility of a rotation around the NC-CN bridge giving rise to the different conformers.

Table 3. Experimental and theoretical Raman and SERS of selected bands $\left(\mathrm{cm}^{-1}\right)$ of indigo and leuco-indigo

\begin{tabular}{|c|c|c|c|c|c|c|}
\hline \multicolumn{4}{|c|}{ Experimental } & \multicolumn{2}{c|}{ Theoretical } & \multirow{2}{*}{ Assignment } \\
\cline { 1 - 5 } $\begin{array}{c}\text { Raman of } \\
\text { indigo (35) }\end{array}$ & $\begin{array}{c}\text { SERS of } \\
\text { indigo }\end{array}$ & $\begin{array}{c}\text { SERS of } \\
\text { leuco-indigo }\end{array}$ & $\begin{array}{c}\text { SERS of } \\
\text { the thread } \\
\text { sample }\end{array}$ & $\begin{array}{c}\text { Raman of } \\
\text { indigo }\end{array}$ & $\begin{array}{c}\text { Raman of } \\
\text { leuco-indigo }\end{array}$ & \\
\hline- & - & 1193 & 1185 & - & 1171 & $\begin{array}{c}v \text { C-C bridge }+ \\
\delta \text { CH (6-member ring) }\end{array}$ \\
\hline- & - & 1338 & 1345 & 1358 & 1334 & $\begin{array}{c}v \text { C-C bridge }+ \\
v \text { C-N (5-member ring) }\end{array}$ \\
\hline
\end{tabular}

$\delta$ : in-plane deformation; $v$ : stretching

As mentioned above, the SERS spectrum of the green thread sample shows bands at 551, 1010, 1107, 1185 and $1345 \mathrm{~cm}^{-1}$ (Figure 7D), that correspond to the yellow dye leuco-indigo. When compared to the SERS of synthetized leucoindigo, slight wavenumber shifts were observed that are likely due to the difference of the matrix (thread or aqueous solution) where the experiments were performed. This is the case, for example, of the band at $1193 \mathrm{~cm}^{-1}$, associated to the pyrrole ring $[40,41]$, seen in the SERS spectra of leuco-indigo, and that appears at $1185 \mathrm{~cm}^{-1}$ in the SERS spectrum of the green thread. In addition, the band at $1338 \mathrm{~cm}^{-1}$ in the leuco-indigo SERS spectrum, related to the NC-CN bridge, shifts to $1345 \mathrm{~cm}^{-1}$ in the SERS spectrum of the thread sample.

The presence of the latter two bands of leuco-indigo, as well as other weaker bands also observed in the SERS spectrum of the sample is the major evidence of the presence of leuco-indigo in the ancient thread. Indeed, this corroborates the fact that the green colour observed is the result of a combination of indigo (blue) and leuco-indigo (yellow). Since leuco-indigo is impossible to obtain as a solid powder, its detection in an ancient thread is novel and generates the question of how leuco-indigo is stabilized on the thread. On the basis of the electronic redistribution involving the NC-CN structural moiety, that the $\mathrm{N}$ lone electron pair plays an important role in the stabilization of the leuco-indigo, most probably through its interaction with positively charged chemical species. This interpretation is supported by a recent work demonstrating that the $\mathrm{N}$ atoms of indigo and leuco-indigo are involved in the interaction with $\operatorname{Ir}(\mathrm{III})$ [42]. In addition, another possibility for the stabilization of leuco-indigo is the formation of a stable metal-complex in the thread resulting from an interaction involving the oxygen atoms of the leuco-indigo form and a cation acting as binder. This idea is supported by the values of the calculated condensed nucleophilic Fukui located on the $\mathrm{N}$ atoms (Table 4) which indicate that leuco-indigo could interact with a cation after a deprotonation to form a cation-ligand complex. Also, on the basis of the Fukui values for the $\mathrm{O}(1)$ and $\mathrm{O}(2)$ atoms, displaying a high electron density, it is possible to propose that any positively charged species (cation) in the environment could stabilize the leuco-indigo conformer; the same cation could interact with the keratin protein as in the case of $\mathrm{Cu}^{+2}, \mathrm{Ni}^{+2}$ and $\mathrm{Zn}^{+2}$ as also demonstrated by recent works [43, 44]. Thus, a stabilized leuco-indigo form should result when the cations of the environment interact with nucleophilic binding sites localized on the $\mathrm{O}$ atoms removing the protons linked to these $\mathrm{O}$ atoms.

Table 4. Fukui nucleophilic values* for selected atoms in indigo and leucoindigo and structural scheme of $\mathbf{A}$ ) indigo and $\mathbf{B})$ leuco-indigo.

\begin{tabular}{|c|c|c|c|c|c|c|c|}
\hline \multicolumn{4}{|c|}{ indigo } & \multicolumn{4}{c|}{ leuco-indigo } \\
\hline Atom & $\begin{array}{c}\text { Nucleophilic } \\
\text { Fukui function } \\
\text { in percent }\end{array}$ & Atom & $\begin{array}{c}\text { Nucleophilic } \\
\text { Fukui function } \\
\text { in percent }\end{array}$ & Atom & $\begin{array}{c}\text { Nucleophilic } \\
\text { Fukui function } \\
\text { in percent }\end{array}$ & Atom & $\begin{array}{c}\text { Nucleophilic } \\
\text { Fukui function } \\
\text { in percent }\end{array}$ \\
\hline $\mathrm{O}(1)$ & 7,60 & $\mathrm{O}(2)$ & 7,62 & $\mathrm{O}(1)$ & 17,19 & $\mathrm{O}(2)$ & 17,15 \\
\hline $\mathrm{C}(1)$ & 1,11 & $\mathrm{C}(4)$ & 1,11 & $\mathrm{C}(1)$ & 1,01 & $\mathrm{C}(4)$ & 1,01 \\
\hline $\mathrm{C}(2)$ & 10,95 & $\mathrm{C}(3)$ & 10,98 & $\mathrm{C}(2)$ & 9,37 & $\mathrm{C}(3)$ & 9,32 \\
\hline $\mathrm{N}(1)$ & 15,93 & $\mathrm{~N}(2)$ & 15,94 & $\mathrm{~N}(1)$ & 11,61 & $\mathrm{~N}(2)$ & 11,63 \\
\hline
\end{tabular}<smiles>CN1C(=O)C(=O)c2ccccc21</smiles>

B)

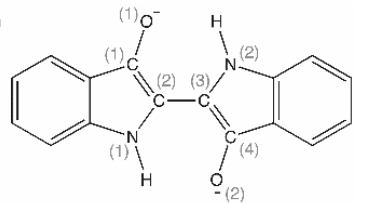

Selected atoms are identified with a number in parenthesis in indigo and leuco-indigo structures.

*The condensed nucleophilic Fukui function was calculated for each atom around the $C$ - $C$ interring bridge bond for the two indigoid structures.

\section{CONCLUSIONS}

A green ancient thread sample from a Chilean mummy turban was analyzed by SERS spectroscopy. Bands associated to biomolecules of the fibre structure were identified. The CIE L*a*b* parameters allowed to confirm that the sample colour is green. SERS results show that the presence of two dyes, indigo and leuco-indigo, are responsible for the green observed colour. Indigo (blue colour component) was identified in the thread from its most recognizable vibrational bands. Leuco-indigo (reduced indigo derivative) displays a yellow colour and its SERS bands, obtained from a synthesized sample, exhibit a great correspondence with some of the bands also seen in the thread SERS spectrum. Particularly, two bands at 1194 and $1338 \mathrm{~cm}^{-1}$ related to modes involving the NC-CN bridge were also identified in the SERS spectrum of the thread (at 1185 and $1345 \mathrm{~cm}^{-1}$, respectively). In this sense, we concluded that the green colour is associated to a combination of indigo and leuco-indigo, both in the thread. The stabilization of leuco-indigo on the thread could be related to an eventual interaction between the $\mathrm{N}$ lone electron pair in the pyrrole moiety with unknown chemical charged species. The formation of a stable metal-complex in the thread, resulting from an interaction involving the oxygen atoms of the leuco-indigo form and a cation, is suggested. This proposition is supported by the calculated condensed nucleophilic Fukui values for $\mathrm{N}$ and $\mathrm{O}$ atoms.

\section{ACKNOWLEDGEMENTS}

FCB acknowledges to Postdoctoral FONDECYT 3150222, EQM150020 FONDEQUIP, CNE 10-1920 project funded by the Universidad de Playa Ancha (concurso regular de investigación año 2018), to San Miguel de Azapa Archaeological Museum of the Universidad de Tarapacá and Laboratorio de Análisis e Investigaciones Arqueométricas (LAIA-UTA) for providing the sample, both from Arica, Chile, and to Mr. Fabián Benavides Reyes from 
Universidad de Concepción - Biblioteca Central, who facilitates the access to reference [20]. MGM acknowledges to CONICYT + PAI / Concurso nacional inserción de capital humano Avanzado en la academia convocatoria año $2017+$ folio 79170025. A.E. Aliaga acknowledges to FONDECYT (grant 11150944) and CONICYT PAI (concurso nacional de inserción en la academia, convocatoria 2015, folio 79150038$)$.

\section{REFERENCES}

1. T. Maugard, E. Enaud, P. Choisy, M. D. Legoy, Identification of an indigo precursor from leaves of Isatis tinctoria (Woad). Phytochemistry. 58, 897904 (2001).

2. W. Maier, B. Schumann, D. Gröger, Biosynthesis of indoxyl derivatives in Isatis tinctoria and Polygonum tinctorium. Phytochemistry. 29, 817-819 (1990).

3. J. C. Splitstoser, T. D. Dillehay, J. Wouters, A. Claro, Early pre-Hispanic use of indigo blue in Peru. Sci. Adv. 2, e1501623 (2016).

4. A. N. Padden, V. M. Dillon, J. Edmonds, M. D. Collins, N. Alvarez, P. John, An indigo-reducing moderate thermophile from a woad vat, Clostridium isatidis sp. nov. Int. J. Syst. Bacteriol. 49, 1025-1031 (1999).

5. A. Roquero, Colores y colorantes de América. An. del Mus. América. 3, 145160 (1995).

6. A. N. Padden, V. M. Dillon, P. John, J. Edmonds, M. D. Collins, N. Alvarez, Clostridium used in mediaeval dyeing. Nature. 396, 225-225 (1998).

7. N. Mermod, S. Harayama, K. N. Timmis, New route to bacterial production of indigo. Bio/Technology. 4, 321-324 (1986).

8. J. Wouters, N. Rosario-Chirinos, Dye Analysis of Pre-Columbian Peruvian Textiles with High Performance Liquid Chromatography and Diode Array Detection. J. Am. Inst. Conserv. 31, 237-255 (1992).

9. L. Degani, C. Riedo, O. Chiantore, Identification of natural indigo in historical textiles by GC-MS. Anal. Bioanal. Chem. 407, 1695-1704 (2015).

10. A. Fiedler, M. Baranska, H. Schulz, FT-Raman spectroscopy - A rapid and reliable quantification protocol for the determination of natural indigo dye in Polygonum tinctorium. J. Raman Spectrosc. 42, 551-557 (2011).

11. R. Mulholland, D. Howell, A. Beeby, C. E. Nicholson, K. Domoney, Identifying eighteenth century pigments at the Bodleian library using in situ Raman spectroscopy, XRF and hyperspectral imaging. Herit. Sci. 5, 1-19 (2017).

12. L. H. Oakley, D. M. Fabian, H. E. Mayhew, S. A. Svoboda, K. L. Wustholz, Pretreatment strategies for SERS analysis of indigo and prussian blue in aged painted surfaces. Anal. Chem. 84, 8006-8012 (2012).

13. M. Ricci, C. Lofrumento, E. Castellucci, M. Becucci, Microanalysis of Organic Pigments in Ancient Textiles by Surface-Enhanced Raman Scattering on Agar Gel Matrices. J. Spectrosc. 2016, 1-10 (2016).

14. M. A. García-Bucio, E. Casanova-González, J. L. Ruvalcaba-Sil, E. ArroyoLemus, A. Mitrani-Viggiano, Spectroscopic characterization of sixteenth century panel painting references using Raman, surface-enhanced Raman spectroscopy and helium-Raman system for in situ analysis of IberoAmerican Colonial paintings. Philos. Trans. R. Soc. A Math. Phys. Eng. Sci. 374, 20160051 (2016)

15. H. Schlüter, Die vorteile der indanthren farbstoffe als kriterium für ihre segmentpezifische anwendung. Textilveredlung. 25, 218-221 (1990).

16. A. Roessler, O. Dossenbach, P. Rys, Electrocatalytic Hydrogenation of Indigo. J. Electrochem. Soc. 150, D1 (2003).

17. A. Roessler, X. Jin, State of the art technologies and new electrochemical methods for the reduction of vat dyes. Dye. Pigment. 59, 223-235 (2003).

18. E. Platania, C. Lofrumento, E. Lottini, E. Azzaro, M. Ricci, M. Becucci, Tailored micro-extraction method for Raman/SERS detection of indigoids in ancient textiles. Anal. Bioanal. Chem. 407, 6505-6514 (2015).

19. O. Otłowska, M. Ślebioda, A. Kot-Wasik, J. Karczewski, M. ŚliwkaKaszyńska, Molecules, in press, doi:10.3390/molecules23020339.

20. G. Focacci, Un cementerio pre-agricola en Playa del Laucho (Arica). Rehue, 49-63 (1969).

21. G. Focacci, Excavaciones en el cementerio Playa Miller 7. Arica (Chile). Chungara, Rev. Antropol. Chil. 3, 23-74 (1974).

22. F. W. Billmeyer, M. Saltzman, Principles of color technology. In: Color and Color Difference Measurement (John Wiley \& Sons, Inc., New York, 1981).

23. R. S. Hunter, R. W. Harold, J. Wiley, The Measurement of Appearance (John Wiley \& Sons, Inc., New York, ed. 2nd, 1987).

24. S. Hoces de la Guardia Ch, P. Brugnoli B, P. Jelvez H, Chromatic range of Arica culture textiles from the late intermediate period: the Inkuñas case. Bol. del Mus. Chil. Arte Precolomb. 16, 67-92 (2011).

25. F. Celis, M. M. Campos-Vallette, J. S. Gómez-Jeria, R. E. Clavijo, G. P. Jara, C. Garrido, Surface-enhanced Raman scattering and theoretical study of the bilichromes biliverdin and bilirubin. Spectrosc. Lett. 49, 336-342 (2016).
26. M. J. Frisch, G. W. Trucks, H. B. Schlegel, G. E. Scuseria, M. A. Robb, J. R Cheeseman, G. Scalmani, V. Barone, B. Mennucci, G. A. Petersson, H. Nakatsuji, M. Caricato, X. Li, H. P. Hratchian, A. F. Izmaylov, J. Bloino, G. Zheng, J. L. Sonnenberg, M. Hada, M. Ehara, K. Toyota, R. Fukuda, J. Hasegawa, M. Ishida, T. Nakajima, Y. Honda, O. Kitao, H. Nakai, T. Vreven, J. A. M. Jr., J. E. Peralta, F. Ogliaro, M. Bearpark, J. J. Heyd, E. Brothers, K. N. Kudin, V. N. Staroverov, R. Kobayashi, J. Normand, K. Raghavachari, A Rendell, J. C. Burant, S. S. Iyengar, J. Tomasi, M. Cossi, N. Rega, J. M. Millam, M. Klene, J. E. Knox, J. B. Cross, V. Bakken, C. Adamo, J. Jaramillo, R. Gomperts, R. E. Stratmann, O. Yazyev, A. J. Austin, R. Cammi, C. Pomelli, J. W. Ochterski, R. L. Martin, K. Morokuma, V. G. Zakrzewski, G. A. Voth, P. Salvador, J. J. Dannenberg, S. Dapprich, A. D. Daniels, O. Farkas, J. B. Foresman, J. V. Ortiz, J. Cioslowski, D. J. Fox, Gaussian (2009).

27. S. I. Gorelsky, AOMix: Program for Molecular Orbital Analysis (2012), (available at http://www.sg-chem.net/).

28. T. Aguayo, C. Garrido, R. E. Clavijo, J. S. Gómez-Jeria, C. Araya Monasterio, M. Icaza, F. Espinoza Moraga, M. M. Campos Vallette, Raman and surface enhanced Raman scattering of a black dyed silk. J. Raman Spectrosc. 44, 1238-1245 (2013).

29. M. C. Caraher, A. Sophocleous, J. R. Beattie, O. O’Driscoll, N. M. Cummins, O. Brennan, F. J. O’Brien, S. H. Ralston, S. E. J. Bell, M. Towler, A. I. Idris, Raman spectroscopy predicts the link between claw keratin and bone collagen structure in a rodent model of oestrogen deficiency. Biochim. Biophys. Acta - Mol. Basis Dis. 1864, 398-406 (2018).

30. A. Kuzuhara, Characterization of keratin fibers using Raman spectroscopy. Kobunshi Ronbunshu. 69, 313-325 (2012).

31. W. Akhtar, H. G. M. Edwards, D. W. Farwell, M. Nutbrown, Fouriertransform Raman spectroscopic study of human hair. Spectrochim Acta Part A. 53, 1021-1031 (1997).

32. A. Kuzuhara, Analysis of structural changes in bleached keratin fibers (black and white human hair) using Raman spectroscopy. Biopolymers. 81, 506-514 (2006).

33. F. Madzharova, Z. Heiner, J. Kneipp, Surface Enhanced Hyper-Raman Scattering of the Amino Acids Tryptophan, Histidine, Phenylalanine, and Tyrosine. J. Phys. Chem. C. 121, 1235-1242 (2017).

34. A. Baran, A. Fiedler, H. Schulz, M. Baranska, In situ Raman and IR spectroscopic analysis of indigo dye. Anal. Methods. 2, 1372 (2010).

35. G. Corales, F. Celis, J. S. Gómez-Jeria, M. Campos, J. J. Cárcamo-Vega, Raman of indigo on a silver surface. Raman and theoretical characterization of indigo deposited on silicon dioxide-coated and uncoated silver nanoparticles. Spectrosc. Lett. 50, 316-321 (2017).

36. J. Seixas de Melo, A. P. Moura, M. J. Melo, Photophysical and Spectroscopic Studies of Indigo Derivatives in Their Keto and Leuco Forms. J. Phys. Chem. A. 108, 6975-6981 (2004).

37. M. M. Sousa, C. Miguel, I. Rodrigues, A. J. Parola, F. Pina, J. S. Seixas De Melo, M. J. Melo, A photochemical study on the blue dye indigo: From solution to ancient Andean textiles. Photochem. Photobiol. Sci. 7, 1353-1359 (2008).

38. C. Liu, J. Xu, S. Q. Gao, B. He, C. W. Wei, X. J. Wang, Z. Wang, Y. W. Lin, Green and efficient biosynthesis of indigo from indole by engineered myoglobins. RSC Adv. 8, 33325-33330 (2018).

39. J. B. Weinrach, D. R. Meyer, T. G. J. Joseph, P. E. Michalski, K. L. Carter D. S. Grubisha, D. W. Bennett, A structural study of sodium dithionite and its ephemeral dihydrate: A new conformation for the dithionite ion. Jorunal Crystallogr. Spectrosc. Res. 22, 291-301 (1992).

40. H. Takahashi, N. Kaneko, K. Miwa, Raman and infrared studies of the structure of the dithionite ion in aqueous solution and force-constants of S2Ox2- type ions. Spectrochim. Acta Part A Mol. Spectrosc. 38, 1147-1153 (1982).

41. G. Socrates, Infrared Characteristic Group Frequencies: Tables and Charts (John Wiley \& Sons, Ltd, Chichester, ed. 3rd, 2004).

42. D. Lin-Vien, N. B. Colthup, W. G. Fateley, J. G. Grasselli, The Handbook of Infrared and Raman Characteristic Frequencies of Organic Molecules (Academic Press, London, ed. 1st, 1991; http://linkinghub.elsevier.com/retrieve/pii/B9780080571164500018).

43. D. V. Konarev, L. V. Zorina, S. S. Khasanov, A. F. Shestakov, A. M. Fatalov, A. Otsuka, H. Yamochi, H. Kitagawa, R. N. Lyubovskaya, Interligand Charge Transfer in a Complex of Deprotonated cis-Indigo Dianions and Tin(II) Phthalocyanine Radical Anions with Cp*Ir III. Inorg. Chem. 57, 583 589 (2018).

44. K. Fukatsu, Rate of metal cation sorption by wool fiber. Sen 'i Gakkaishi. 44 238-242 (1988).

45. D. Balköse, H. Baltacioğlu, Adsorption of heavy metal cations from aqueous solutions by wool fibers. J. Chem. Technol. Biotechnol. 54, 393-397 (1992). 